* This is the accepted manuscript of a paper published in Science of the Total Environment. The formatted version may be accessed at https://www.sciencedirect.com/science/article/pii/S0048969718318114

This paper is available under a CC-BY-NC-ND license.

\title{
Predictors of coastal stakeholders' knowledge about seawater desalination impacts on marine ecosystems
}

Nadine Heck (corresponding author) ${ }^{\mathrm{a}, \mathrm{b}}$

Karen Lykkebo Petersen ${ }^{c}$

Donald C. Potts ${ }^{\mathrm{d}}$

Brent Haddad ${ }^{\mathrm{e}}$

Adina Paytan ${ }^{\mathrm{a}, \mathrm{c}}$

a Ocean Sciences, University of California, Santa Cruz, 1156 High Street, Santa Cruz CA 95064, USA,nheck@ucsc.edu

b Institute of Marine Sciences, University of California, Santa Cruz, 1156 High St., Santa Cruz, CA 95064, USA

c Department of Earth and Planetary Sciences, University of California, Santa Cruz, 1156 High Street, Santa Cruz, CA 95064, USA

d Department of Ecology and Evolutionary Biology, University of California, Santa Cruz, 1156 High St., Santa Cruz, CA 95064, USA

e Environmental Studies, University of California, Santa Cruz, 1156 High St., Santa Cruz, CA 95064, USA 


\section{Abstract}

This study investigates variables that shape coastal stakeholders' knowledge about marine ecosystems and impacts of seawater desalination. The influence of trans-situational and situation-specific variables on self-assessed and factual knowledge among coastal residents and commercial marine stakeholders. Data were collected using a questionnaire based survey administered to a random sample of coastal residents and commercial marine stakeholders in eight communities in central California. Knowledge of biological features was higher than knowledge of physical and chemical processes. Both trans-situational and situation-specific variables were significant predictors of knowledge, in particular gender, education, and ocean use patterns. TV and social media were the only information sources that correlated negatively with knowledge. Predictors for distinct types of knowledge were different and provide insights that could help target specific ocean literacy gaps. The study also finds that commercial marine stakeholders were more knowledgeable than other coastal residents. Having an economic stake in the marine environment appears to be a strong motivation to be more educated about the ocean.

\section{Graphical abstract}

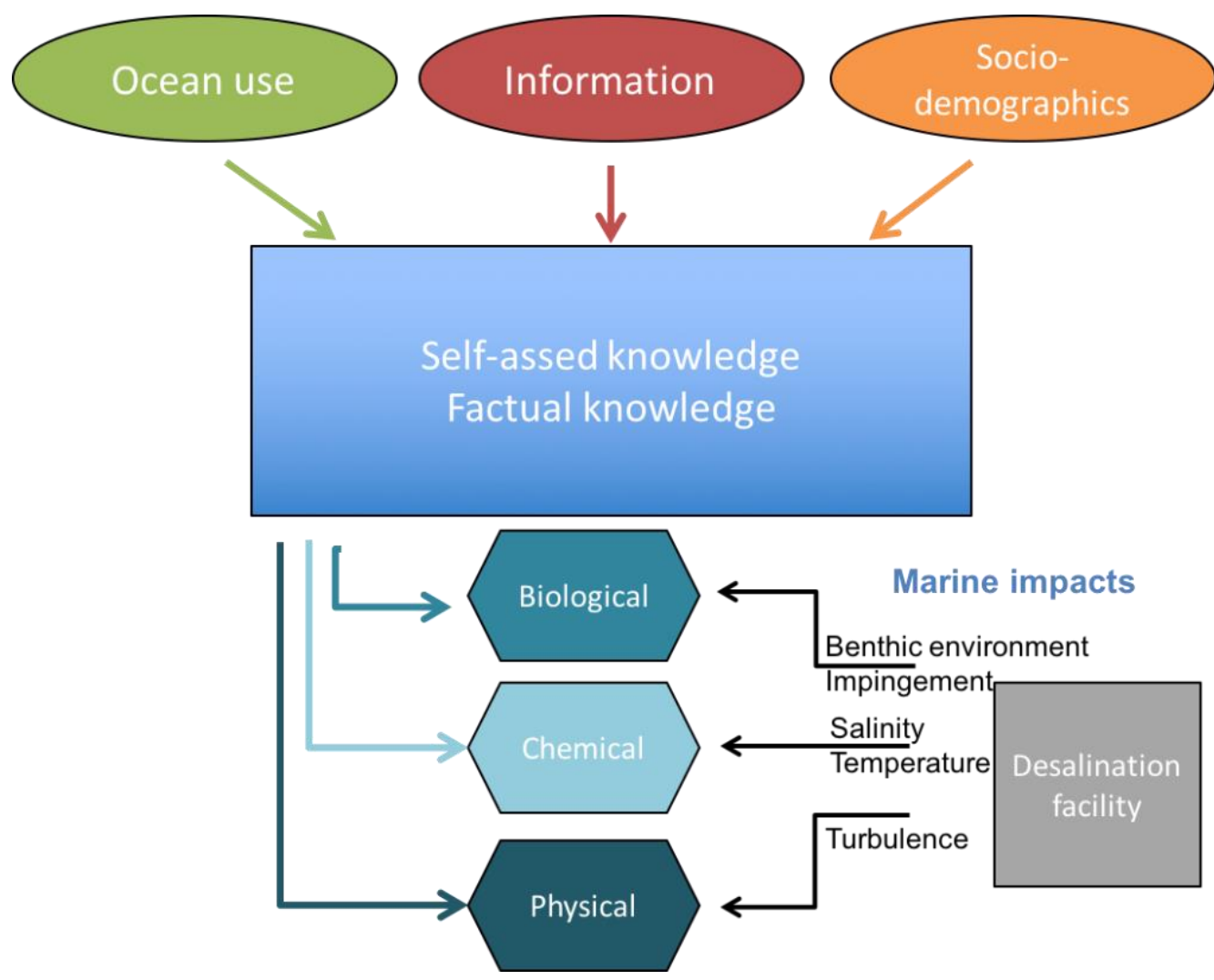




\section{Introduction}

Coastal zone and marine management is increasingly moving towards more participatory approaches that engage stakeholders in management and decision-making processes. Consequently, the engagement of coastal residents as a stakeholder group is increasingly becoming an integral part of creating coastal and marine policies. Stakeholder participation incorporates local preferences in the management of coastal and marine resources (Marre et al. 2016, Rogers 2013, Vanclay 2012). An engaged public is also seen as essential for successfully addressing complex ocean- and coastal-related issues, including balancing the use and conservation of marine resources, and realizing future benefits of the ocean (National Ocean Council 2013).

Because coastal citizens can significantly influence decision-making processes, public knowledge about the ocean and its resources is critical for ensuring that the public both understands the implications of marine and coastal policies, and can engage in discussions and decision-making about the use of ocean resources in an informed way (Steel et al. 2005a, Steel et al. 2005b). The recent U.S. National Ocean Policy, for example, called for increasing ocean and coastal literacy to empower coastal communities and enable them to become better stewards of ocean resources (National Ocean Council 2013). At the same time, recent research suggests that the public has a poor understanding of the structure and functioning of coastal and marine ecosystems, of how humans affect the health of these systems, and of basic ocean science principles, despite the fact that a high percentage of the human population lives in coastal areas (Fletcher et al. 2009, Capstick et al. 2016). Therefore, understanding the level of public knowledge about marine and coastal systems and identifying variables that are related to higher knowledge are critical for identifying misconceptions and knowledge gaps, and for tailoring communication and outreach programs.

Two theories have been proposed to explain differences in knowledge about environmental issues. One theory states that environmental knowledge is primarily shaped by 'trans-situational' socio-economic variables that apply in multiple settings. Examples include level of formal education, income, education, age, and gender. (Lovrich and Pierce 1984). The other theory argues that knowledge is shaped more by contextual situation-specific factors that might increase knowledge irrespective of socio-economic status. These situational factors are more motivational in character and might increase knowledgeseeking behavior by those having a stake in a policy outcome, or having strong views on specific policies (Pierce 1992, Steel et al. 1990). For example, people who live close to the ocean, use the ocean for recreation or commercial purposes, or have a strong attachment to ocean areas, may be very interested 
in the management of marine resources and thus may be highly knowledgeable about the ocean in general and management issues in particular (Perry et al. 2014, Cicin-Sain and Knecht 2000). In addition, ocean literacy depends on the information sources used to learn about the ocean. Understanding where people learn about the ocean is essential to tailoring and targeting communication strategies and ensuring that credible information reaches the public and increases ocean literacy (Fauville et al. 2015). Our study expands on existing literature by investigating public literacy in the context of seawater desalination and its impacts on marine ecosystems. Seawater desalination is an emerging sector in the USA that is likely to grow in the future. Even though seawater desalination is highly valued for its ability to provide a potable water supply that is independent of climate, the technology remains controversial due to high costs and potential environmental impacts (Liu et al. 2013, Fuentes-Bargues 2014). On a global scale, desalination facilities have high energy demands that are likely to contribute $\mathrm{CO}_{2}$ to the atmosphere (Lattemann and Höpner 2008, Einav et al. 2003). More localized concerns about direct impacts on coastal ecosystems include mortality of marine organisms due to impingement and entrainment during water intake, impacts of brine discharge (including mortality of marine life), changes in seawater quality, adverse effects on fish resources, degradation of marine habitats due to toxic concentrations of brine, anoxic or hypoxic conditions, and stress from turbulent mixing at the point of discharge (Latteman 2009, El Wahab and Hamoda 2012).

Our study extends the limited research on public knowledge about the ocean. Previous studies have explored awareness of coastal and marine environmental issues (Fletcher et al. 2009), general ocean literacy (Fauville et al. 2015, Steel et al 2005a), and public ocean literacy in the context of specific marine issues such as marine protected areas (Perry et al. 2014) and fisheries (Steel et al 2005b). Our study expands this literature by investigating transitional and motivational variables, and the influences of information use on public knowledge about impacts of desalination on marine ecosystems.

We explore socio-demographic factors, situation-specific factors, and information sources associated with higher levels of self-assessed and factual knowledge about biological, physical, and chemical processes important for understanding desalination impacts on marine areas. In addition, we investigate whether commercial marine users are more knowledgeable about policy-relevant aspects of desalination and its impacts on the ocean than other coastal residents. As these stakeholders use the ocean for different purposes, their motivation for learning about the ocean and thus their levels of knowledge may be different. 


\section{Methods}

\subsection{Study area}

The study was conducted in coastal communities adjacent to Monterey Bay, which is part of the Monterey Bay National Marine Sanctuary (MBNMS) in central California (Fig. 1).

Fig. 1 Locations of Monterey Bay, proposed desalination plants, and surveyed communities (small map indicates location of Monterey Bay in California)

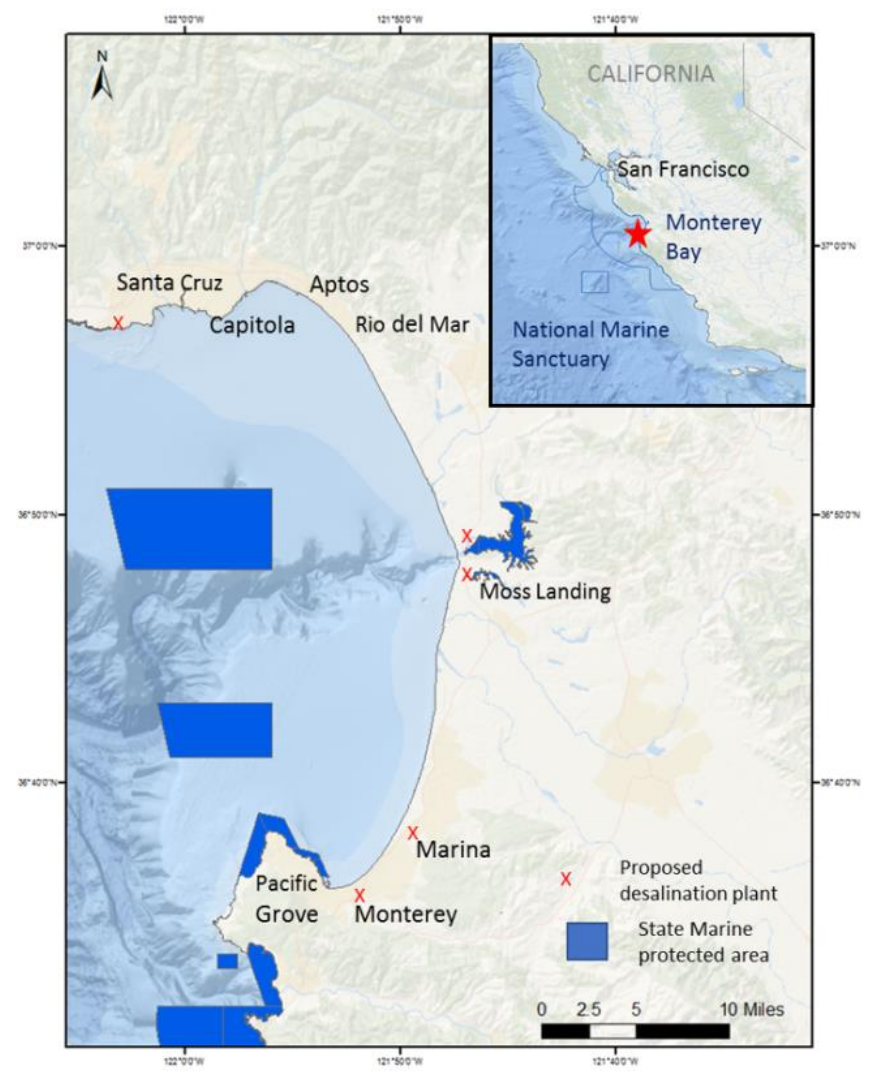

The MBNMS has been a federal marine protected area since 1992, and is managed by the National Oceanic and Atmospheric Administration (NOAA). The Sanctuary has a shoreline length of 276 miles and an area of 6,094 square statute miles (NOAA 2017). Five seawater desalination plants have been proposed in communities around Monterey Bay. Seawater desalination is recognized as a regional issue of concern for the MBNMS, and NOAA has developed a Desalination Action Plan that recommends using regional planning efforts for proposed desalination plants within the boundaries of the Sanctuary (NOAA Monterey Bay National Marine Sanctuary and National Marine Fisheries Service 2010). As part of this 
process, the public has been encouraged to participate in discussions about proposed desalination plants in public hearings and open house meetings, and to comment on Environmental Impact Reports for desalination plants. The public has also been invited to comment on any proposed revisions to the existing management plan for the Sanctuary.

\subsection{Questionnaire based survey}

Data were collected via a questionnaire-based survey in June and July 2016 among multiple coastal stakeholder groups around Monterey Bay, including coastal residents and commercial marine users. We first tested the survey instrument in a pilot study of 30 respondents. The survey instrument was well understood, and no modifications were necessary. Coastal residents were sampled in randomly selected households based on postal records in eight communities directly bordering Monterey Bay: Santa Cruz, Capitola, Aptos, Rio del Mar, Moss Landing, Marina, Monterey, and Pacific Grove. We applied a stratified sampling approach to account for differences in the size of participating communities. Questionnaires for households were either administered in person or left at the door with a cover letter stating that the questionnaire would be picked up 2 days later. Commercial marine user groups licensed to operate in the MBNMS, including whale watching, sea kayaking, and scuba diving operators, were sampled using a census sampling approach. Commercial marine user groups were surveyed at their place of work and the main owner of the business was asked to fill out the survey. Due to limited time and capacity, commercial fishermen were not included in the study.

In total, we surveyed 1150 coastal stakeholders consisting of 1116 residents and 34 commercial marine users. The overall response rate was $34 \%(n=391)$ with response rates of $32.5 \%$ for residents $(n=363)$, $81.8 \%$ for scuba diving operators $(n=9), 90 \%$ for whale watching operators $(n=8)$, and $100 \%$ for sea kayaking operators $(n=11)$. Similar to previous studies of ocean-related public knowledge (SteelSmith et al. 2005, Perry et al. 2014), residents' literacy was evaluated in two ways - self-assessed levels of knowledge and factual knowledge. The distinction between self-assessed and factual knowledge is important since knowledge is usually highly subjective (Guzman 2009). Self-assessed knowledge is measured by assessing what a person believes he or she knows. Factual knowledge is measured by whether a person knows the correct answer to a specific knowledge question (Perry et al. 2014). Self-assessed knowledge was examined by asking about understanding of nine specific marine and coastal terms, based on a 3-point scale of 1= have not heard about it, 2= heard about it but don't know its meaning, and $3=$ know the meaning. Three terms referred to marine ecosystems that can be affected by desalination (plankton, biodiversity, algal blooms), three addressed physical aspects relevant to 
seawater desalination (benthic, upwelling, saltwater intrusion), and three were related to the desalination process itself (brine, reverse osmosis, greenhouse gas emission). These terms are critical for understanding marine ecosystem features that can be affected by seawater desalination and for understanding the basic processes involving operation of seawater desalination plants.

Factual knowledge was measured by seven multiple choice questions (Table 1), including three questions about biology, and two questions each about chemical and physical processes that are important for understanding the desalination process and its impacts on marine ecosystems.

Table 1 Multiple choice questions to test factual knowledge with correct answers indicated in bold

\section{Questions}

Biological

Water taken from the open ocean contains [fish larvae; other small marine life; plankton; all three; none of these; don't know]

Plankton [is an important source of food for marine wildlife; has no role in the food web; is only important to fish; don't know]

Changes in temperature and ocean chemistry in the ocean [have no effect on marine life; can affect survival of marine organisms and biological diversity; don't know]

Chemical

The ocean [absorbs carbon dioxide from the air; does not interact with the atmosphere; don't know]

Water discharged by a desalination plant directly back into the ocean has [the same amount of salt as ocean water; more salt than ocean water; less salt than ocean water; don't know] Physical

Ocean water for desalination can be taken [from the open ocean; from beneath the ocean floor; both; don't know] Water with more salt than ocean water [sinks to the bottom; floats to the surface; don't know]

We included questions related to all three areas to identify predictors for different types of knowledge. In addition, we collected socio-demographic information on gender, age, and level of education (Table 2). There were almost equal numbers of male and female respondents, and the coastal stakeholders surveyed were highly educated with more than $90 \%$ having a university degree. 
The assessed situation-specific variables covered dependency of livelihoods on marine areas in Monterey Bay (Table 2) and time spent in the Sanctuary, based on frequencies of undertaking ten marine activities in the area (Table 3 ). Use of information sources was assessed by how frequently people used 11 different information sources to learn about the ocean and coastal issues, including seawater desalination (Table 3).

Table 2 Coding and findings of dependent variables $(n=391)$

\begin{tabular}{llr}
\hline Variable & Coding & Sample \\
\hline Gender & Male (1) & $49.9 \%$ \\
& Female (0) & $50.1 \%$ \\
Age & Continuous & \\
& $18-34$ & $17.7 \%$ \\
& $35-60$ & $38.5 \%$ \\
& $>61$ & $43.8 \%$ \\
Education & & $1.9 \%$ \\
& Less than high school (1) & $60.3 \%$ \\
Undergraduate (2) & $37.8 \%$ \\
Givelihood dependency & Graduate (3) & $17.5 \%$ \\
& Yes (1) & $82.5 \%$ \\
\hline
\end{tabular}

We evaluated internal consistencies in the responses by calculating Cronbach's alpha before creating two composite variables of ocean use and information use. Since the Cronbach's alpha coefficients were

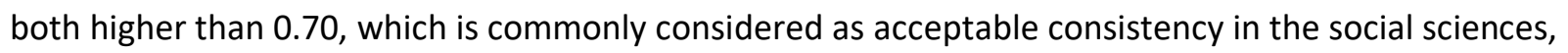
we retained all variables in each composite variable. 
Table 3 Description and reliability analysis of ocean use and information use

\begin{tabular}{|c|c|c|c|}
\hline Variable & Mean & SD & Cronbach's' Alpha \\
\hline Ocean use (mean) ${ }^{1}$ & 2.11 & 0.598 & 0.784 \\
\hline Commercial fishing & 1.21 & 0.636 & \\
\hline Recreational fishing & 1.66 & 1.049 & \\
\hline Surfing & 1.75 & 1.141 & \\
\hline swimming & 2.20 & 1.121 & \\
\hline Boating & 2.18 & 1.195 & \\
\hline Wildlife viewing & 3.59 & 1.142 & \\
\hline Beach walking & 3.84 & 0.947 & \\
\hline Diving & 1.53 & 1.056 & \\
\hline Aquaculture & 1.28 & 0.697 & \\
\hline Sea kayaking & 1.85 & 1.106 & \\
\hline Information use (mean) ${ }^{2}$ & 2.39 & 0.587 & 0.827 \\
\hline TV & 2.56 & 1.179 & \\
\hline Newspaper & 2.99 & 1.186 & \\
\hline Internet & 3.37 & 1.120 & \\
\hline Radio & 2.44 & 1.182 & \\
\hline Public hearings & 1.66 & 0.877 & \\
\hline National Marine Sanctuary & 2.04 & 1.050 & \\
\hline Monterey Bay aquarium & 2.76 & 1.078 & \\
\hline Scientific presentations & 1.98 & 1.074 & \\
\hline Social media & 2.10 & 1.219 & \\
\hline Family and friends & 2.76 & 1.078 & \\
\hline NGO & 2.45 & 1.107 & \\
\hline Pro-Desalination group & 1.71 & 0.907 & \\
\hline Anti-desalination group & 1.72 & 0.929 & \\
\hline
\end{tabular}

${ }^{1}$ Assessed on 5-point scale from never (1) to almost every day (5)

${ }^{2}$ Assessed on a 5-point scale from never (1) to very frequently (5)

Statistical analyses were conducted using IBM SPSS.24, a statistical software package for the social sciences. As the main emphasis was on identifying variables that shape public literacy about marine 
systems and desalination impacts, we did not weight the data to account for potential differences between our sample and census data for the region. We used Spearman's rank correlation analysis to evaluate associations of ocean use and information use with self-assessed and factual knowledge. In addition, we applied linear regression models to identify predictors of self-assessed and factual knowledge. For the linear regression models, we used the mean of ocean use and information use as predictor variables.

\section{Results}

\subsection{Self-assessed knowledge}

Coastal stakeholders reported high self-assessed knowledge of scientific terms that are important for understanding impacts of desalination on marine ecosystems (Fig 2). Knowledge was particularly high for ecological terms that can be affected by water intake and brine discharge (e.g., plankton, biodiversity, and algal blooms), and for terms related to climate change such as greenhouse gas, which is emitted because of the high-energy demand of desalination plants. Knowledge about desalinationspecific terms (e.g., brine, reverse osmosis) and about physical terms such as "upwelling" and "benthic" was lower.

Fig. 2 Self-assessed knowledge of ocean terminology $(\mathrm{N}=391)$

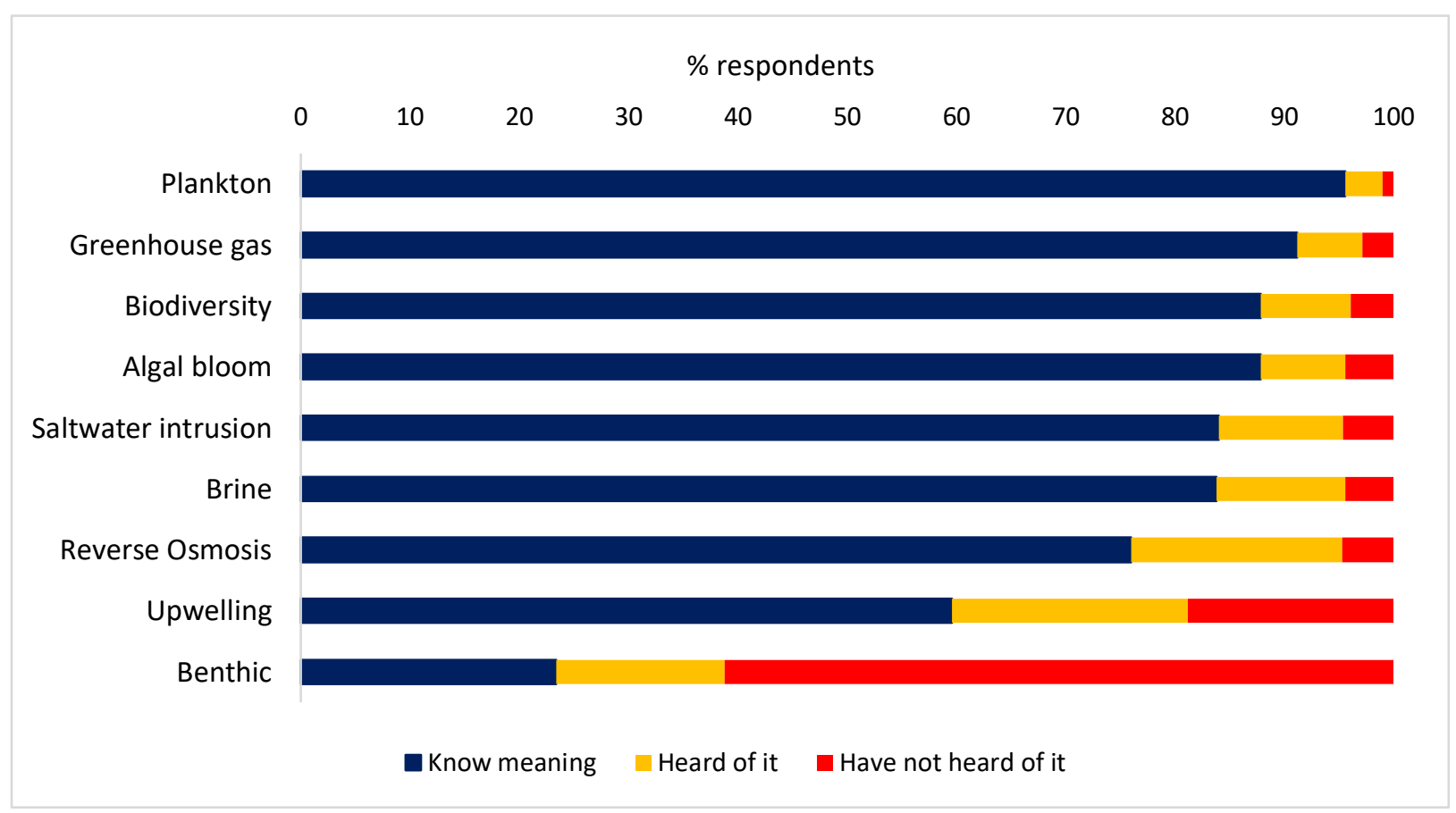




\subsection{Factual knowledge}

Factual knowledge was high for questions about biological aspects of the ocean with $89.9 \%$ of respondents answering these questions correctly (Table 4). Knowledge was lowest for physical processes, with only $39.2 \%$ of respondents giving the correct answer and more than $30 \%$ indicating they had no knowledge about these processes.

Table 4 Frequencies (\%) of responses to factual ocean knowledge questions ( $N=391$ ) grouped by discipline

\begin{tabular}{lrrr}
\hline & Correct (\%) & Incorrect (\%) & Don't know (\%) \\
\hline Biological & 90.5 & 2.2 & 7.3 \\
Chemical & 73.9 & 6.7 & 19.4 \\
Physical & 40.1 & 24.9 & 35 \\
\hline
\end{tabular}

Residents were highly knowledgeable about biological aspects, including marine organisms: e.g., more than $90 \%$ of respondents were aware that plankton is an important source of food for marine life and that changes in temperature and water chemistry (e.g., due to brine discharge) can affect the survival of marine organisms (Fig. 3). In contrast, knowledge about physical processes was relatively low: $69.6 \%$ of respondents knew about the high salt concentration of brine discharged by a desalination facility, but fewer than half $(49.9 \%)$ of respondents knew that water with more salt than ocean water sinks to the ocean floor where it can affect the benthic environment. This contrast suggests an incomplete understanding of the potential impacts on marine environments due to the operation of desalination facilities. In addition, only $28.4 \%$ of respondents knew that water for desalination can be taken from either the open ocean or from beneath the ocean floor. This distinction is important, in the context of seawater desalination, because open ocean intake is often seen as environmentally more detrimental than other intake options, such as beneath the ocean floor. The results also suggest that knowledge about physical benthic features is particularly low, as was also the case for self-assessed knowledge. Further analysis revealed that the number of terms known and the number of factual knowledge questions answered correctly were significantly correlated (Spearman's rho=0.506, $p<0.001$ ), which suggests that in this community self-assessed knowledge is a good predictor of factual knowledge about marine issues. 
Fig. 3 Factual knowledge of the ocean $(\mathrm{N}=391)$

$\%$ of respondents

$\begin{array}{lllllllllll}0 & 10 & 20 & 30 & 40 & 50 & 60 & 70 & 80 & 90 & 100\end{array}$

Plankton is an important source of food for marine life

Changes in temperature and chemistry in the ocean can affect the survival of marine organisms and biological...

Water for desalination taken from open ocean contains fish larvae, other small marine life, plankton

The ocean absorbs carbon dioxide from the air

Water discharged by a desalination plant back into the ocean has more salt than ocean water
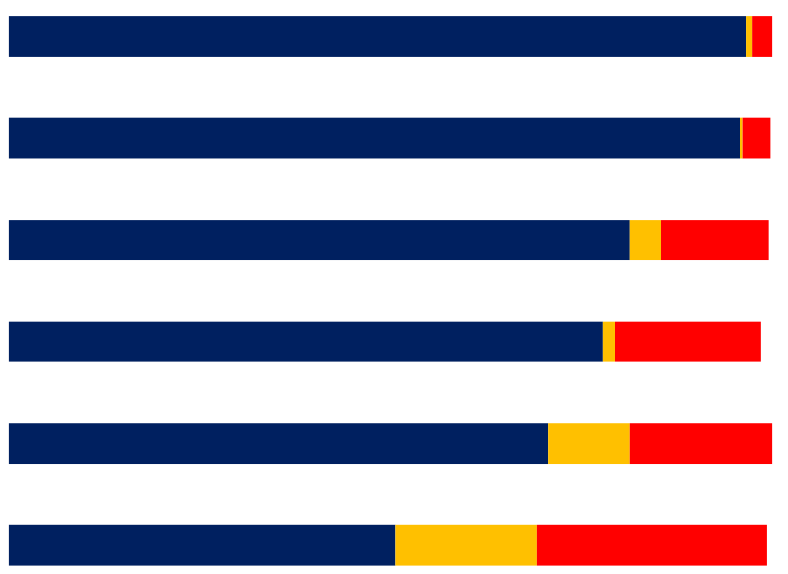

Water with more salt than ocean water sinks to the bottom

Ocean water for desalination can be taken from the open ocean and beneath the ocean floor

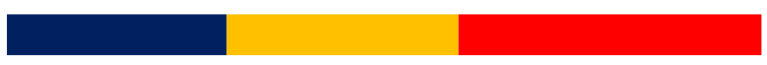

- Correct Incorrect Don't know

\subsection{Differences in knowledge of coastal residents and commercial marine users}

We conducted t-tests to evaluate whether mean levels of factual and self-assessed knowledge among coastal residents differed from those of commercial marine users. Engagement in commercial activities appeared to increase knowledge about the ocean, since commercial users had significantly higher selfassessed and factual knowledge than other coastal residents (Table 5).

Table 5 Differences in knowledge among coastal residents and commercial marine users

\begin{tabular}{lcccc}
\hline & Coastal residents & Commercial users & $\mathrm{t}$ & $\mathrm{p}$ \\
\hline Self-assess knowledge ${ }^{1}$ & 6.7239 & 7.7818 & -3.602 & 0.000 \\
Factual knowledge $^{2}$ & 4.8589 & 5.5818 & -3.045 & 0.002 \\
& & & \\
\hline${ }^{1}$ \# of terms known & & & \\
${ }^{2}$ \# of questions answered correctly & & &
\end{tabular}




\subsection{Predictors of ocean knowledge}

Socio-demographic, motivational, and information use variables were statistically significant predictors of self-assessed and factual knowledge (Table 6). Self-assessed knowledge was predicted by education $(p<0.05)$, gender, recreational ocean use, and information use (all $p<0.01$ ). Males, people with higher education levels, those who frequently use the ocean for recreational activities, and those who frequently learn about the ocean from a variety of information sources had higher self-assessed knowledge. Factual knowledge was predicted by education level, recreational and commercial ocean use, and information use (all $p<0.05$ ). Respondents with higher education levels, those who frequently use marine areas for recreational and commercial purposes, and who use a variety of information sources to learn about the ocean had higher factual knowledge. Age was not associated significantly with either type of knowledge.

Table 6 Multiple linear regression coefficients for self-assessed knowledge of ocean terminology (\# of terms known) and factual knowledge (\# of questions answered correctly)

\begin{tabular}{lcccccc}
\hline & \multicolumn{3}{c}{ Self-assessed knowledge $^{\mathrm{a}}$} & \multicolumn{3}{c}{ Factual knowledge $^{\mathrm{b}}$} \\
\hline & $\mathrm{B}$ & S.E. & Beta & B & S.E. & Beta \\
\hline (Constant) & 2.682 & 0.717 & & 3.338 & 0.621 \\
Education & 0.516 & 0.259 & $0.105^{*}$ & 0.527 & 0.224 & $0.128^{*}$ \\
Age & 0.001 & 0.007 & 0.084 & -0.004 & 0.006 & -0.036 \\
Gender & 0.847 & 0.232 & $0.199 * *$ & 0.366 & 0.201 & 0.102 \\
Livelihood dependency & -0.357 & 0.379 & -0.063 & -0.235 & 0.328 & -0.050 \\
Fishing & -0.183 & 0.186 & -0.063 & -0.286 & 0.161 & -0.118 \\
Recreational ocean use & 0.740 & 0.205 & $0.252 * *$ & 0.408 & 0.178 & $0.166 *$ \\
Commercial marine use & 0.787 & 0.428 & 0.129 & 0.825 & 0.370 & $0.160 *$ \\
Information use & 0.543 & 0.203 & $0.152 * *$ & 0.463 & 0.175 & $0.154 *$ \\
\hline
\end{tabular}

${ }^{a} R=0.423 R^{2}=0.179 ;$ adjusted $R=0.129 ; F=8.515 ; p<0.001$

${ }^{b} R=0.359 ; R^{2}=0.129$ adjusted $R=0.083 ; F=5.776 ; p<0.001$

Sign. ${ }^{*} \mathrm{p}<0.05 ; * * \mathrm{p}<0.001$

We calculated Spearman's rank correlation coefficients for all information sources with self-assessed and factual knowledge. Nine of fourteen information sources were correlated significantly (most $\mathrm{P}<.01$; a few $P<.05)$ with higher ocean knowledge, with the same nine sources being significant for both self- 
assessed and factual knowledge (Table 7). Learning about the ocean and seawater desalination from family and friends, TV and social media, were not significantly correlated with higher knowledge, even though they were among the most often used information sources in our study. In fact, social media and TV correlated negatively with both self-assessed and factual knowledge. In contrast, learning about the ocean on the internet, in public hearings, or from presentation by regional scientists was significantly correlated with higher knowledge in both categories. Correlation coefficients of targeted outreach efforts, such as public hearings and material distributed by NGOs and desalination groups, were slightly higher than correlation coefficients for mainstream media such as newspapers, the Internet, and radio. Targeted education thus seemed to be slightly more effective in increasing ocean related knowledge.

Table 7 Spearman rank correlation coefficients between situation-specific variables and information use with self-assessed and factual knowledge

\begin{tabular}{lcc}
\hline \multicolumn{1}{c}{ Information source } & Self-assessed knowledge & Factual knowledge \\
\hline TV & -0.096 & -0.051 \\
Newspaper & $0.128^{*}$ & $0.105^{*}$ \\
Internet & $0.261^{* *}$ & $0.132^{*}$ \\
Radio & $0.111^{*}$ & $0.133^{*}$ \\
Public hearings & $0.242^{* *}$ & $0.193 * *$ \\
National Marine Sanctuary & & \\
outreach & $0.189 * *$ & $0.142 * *$ \\
Monterey Bay Aquarium & 0.098 & 0.062 \\
Scientific presentations & $0.329 * *$ & $0.199 * *$ \\
Social media & -0.030 & -0.028 \\
Family and friend & 0.002 & 0.017 \\
NGOs & $0.164 * *$ & $0.158^{* *}$ \\
Pro-desalination group & $0.209 * *$ & $0.137^{* *}$ \\
Anti-desalination group & $0.182 * *$ & $0.136 * *$ \\
\hline
\end{tabular}

Sign. ${ }^{*} p<0.05 ;{ }^{* *} p<0.001$

Regression analysis also revealed that different categories of factual knowledge were associated with distinct socio-demographic and information source variables (Table 8). Knowledge about physical processes was predicted by gender and information sources used to learn about the ocean (both $p$ 
$<0.05$ ); knowledge about biological aspects was predicted by education ( $p<0.05)$; while education ( $p$ $<0.05)$ and gender $(p<0.01)$ were significant predictors of knowledge about chemical processes. In contrast, neither ocean use variables nor livelihood dependency were associated significantly with any category of knowledge. Although not statistically significant, the use of social media and TV was negatively correlated with knowledge. Further regression analysis also revealed that the different types of factual knowledge regressed significantly with different variables (Table 9). Socio-demographic variables including gender and level of education were significant predictors of all three knowledge types. Education regressed significantly with knowledge about chemical and biological aspects while gender was a predictor for knowledge about physical and chemical processes. Information use also significantly regressed with knowledge about physical processes. Ocean use and livelihood dependency did not regress significantly with any particular knowledge type.

Table 8 Multiple linear regression coefficients for factual knowledge types (number of questions answered correctly)

\begin{tabular}{|c|c|c|c|c|c|c|c|c|c|}
\hline & \multicolumn{2}{|c|}{ Physicala } & \multirow[b]{2}{*}{ Beta } & \multicolumn{2}{|c|}{ Biologicalb } & \multicolumn{2}{|c|}{ Chemical } & \multirow[b]{2}{*}{ SE } & \multirow[b]{2}{*}{ Beta } \\
\hline & B & SE & & B & SE & Beta & B & & \\
\hline (Constant) & 0.260 & 0.258 & & 2.234 & 0.226 & & 0.736 & 0.249 & \\
\hline Education & 0.138 & 0.092 & 0.083 & 0.204 & 0.080 & $0.140 *$ & 0.226 & 0.088 & $0.138 *$ \\
\hline Age & -0.001 & 0.003 & -0.024 & .001 & 0.002 & -0.024 & -0.001 & 0.002 & -0.036 \\
\hline Gender & 0.177 & 0.082 & $0.124 *$ & -0.015 & 0.072 & -0.012 & 0.261 & 0.080 & $0.184 * *$ \\
\hline \multicolumn{10}{|l|}{ Livelihood } \\
\hline dependency & -0.166 & 0.135 & -0.087 & -0.056 & 0.119 & -0.034 & -0.012 & 0.130 & -0.006 \\
\hline Ocean use & -0.007 & 0.083 & -0.006 & 0.069 & 0.073 & 0.070 & 0.120 & 0.080 & 0.109 \\
\hline \multicolumn{10}{|l|}{ Commercial } \\
\hline marine use & 0.260 & 0.154 & 0.126 & 0.186 & 0.135 & 0.103 & 0.159 & 0.149 & 0.078 \\
\hline \multicolumn{10}{|l|}{ Information } \\
\hline use & 0.169 & 0.073 & $0.141 *$ & 0.091 & 0.064 & 0.087 & 0.097 & 0.070 & 0.081 \\
\hline
\end{tabular}

Sign. ${ }^{*} p<0.05 ; * * p<0.001$

${ }^{\text {a }} R=0.230 ; R^{2}=0.054$, adjusted $R^{2}=0.033, F=2.570, p=0.014$

${ }^{b} R=0.241 ; R^{2}=0.058$, adjusted $R^{2}=0.037, F=2.745, p=0.009$

${ }^{c} R=0.326 ; R^{2}=0.106$, adjusted $R^{2}=0.086, F=25.321 p=0.000$ 


\section{Discussion}

Our study explored variables influencing coastal stakeholders' knowledge about impacts of desalination on marine ecosystems in central California. Overall, coastal stakeholders' knowledge about marine processes and impacts in our study was higher than in previous studies of ocean literacy that reported low levels of public ocean knowledge (Xu et al. 2006, Perry et al. 2014, Jones et al. 2011). Knowledge about biological processes was particularly high and not confined to the charismatic marine mammals (e.g., whales and dolphins) that are typically of greatest public interest (Guest et al. 2015, Jefferson et al. 2014); our respondents were also knowledgeable about non-charismatic organisms such as plankton and processes such as algal blooms.

Our finding of higher levels of biological knowledge than about physical or chemical processes is consistent with findings by Guest et al. (2015) who reported less knowledge about salinity and bathymetry than knowledge about species or other biological questions among high school students. For desalination, knowledge of physical and chemical aspects is necessary for understanding potential impacts of both brine discharge and water intake on marine ecosystems, including benthic environments. A greater educational emphasis on broader ecosystem processes that combine biological with physical and chemical aspects may lead to more comprehensive public understanding of the ocean in general, and of desalination impacts in particular. The limited knowledge of less visible physical and chemical processes and benthic features among our respondents was similar to findings of previous studies (Beldon 1999, Compas et al. 2007). Increasing exposure to these concepts in ocean outreach and education efforts should increase knowledge about these aspects of oceanography. In addition, factual knowledge about desalination-specific impacts by our respondents was slightly lower than their broader knowledge of marine ecosystems. More broadly, development of new economic sectors and technologies may require targeted education efforts to enable coastal stakeholders, including coastal residents, to engage in decision-making in an informed way. Without such efforts, engagement of the public might not lead to well-informed decisions and may even challenge the legitimacy of participatory approaches (Fung 2015). By leveraging existing public knowledge about marine systems in general, outreach and education efforts should increase understanding of sector-specific knowledge and its connection to marine ecosystems.

Our findings demonstrate that both trans-situational and situation-specific variables influence ocean knowledge, indicating that both theories contribute to explanations of knowledge about marine issues. 
This is consistent with results of Steel et al. (2005b) in the context of fisheries. The gender gap present in our data for both self-assessed and factual knowledge, with women being less knowledgeable than male respondents, has also been found in previous studies (e.g., Steel et al. 2005a). Our results indicate that the gap is primarily evident for knowledge of physical and chemical processes, which suggests that focusing education more on these processes, especially for women, is likely to reduce this persistent gender gap. While many efforts to increase interests in and knowledge of STEM sciences already exist in high schools (Levine et al. 2015), additional efforts directed towards adults might ensure a more equal understanding of environmental processes across genders. Without such efforts, women may not participate as equals in coastal decision-making processes, or they may have less knowledge on which to base informed decisions.

We did not detect an effect of age on ocean knowledge, which parallels findings about public knowledge of sharks and their conservation by O'Bryhim and Parsons (2015), who also found no connection between age and public knowledge. Both our findings and those of $\mathrm{O}^{\prime}$ Bryhim and Parsons are in contrast to work by Steel et al (2005a) who reported a significant impact of age on knowledge. This variation in the influence of age, suggests that other socio-economic factors may be more reliable predictors of public ocean literacy.

Among context-specific variables, frequent use of the ocean was a significant predictor of knowledge. This is consistent with previous studies that revealed that frequent visits to the coast lead to higher ocean-related knowledge (Steel et al 2005a) and suggests that marine use patterns shape interest in learning about marine issues (Wiener et al. 2016). Engagement with coastal and marine environments thus seems to be an important factor shaping public ocean knowledge. Since ocean use did not appear to increase a specific category of ocean-related knowledge (i.e., biological, physical, desalination), it appears that frequent engagement with the marine environment may lead to greater knowledge about all aspects of the ocean. Therefore, marine outreach and education efforts that contain active engagement components with marine and coastal ecosystems are likely to be most effective in shaping public ocean literacy.

Our study further found that commercial marine users were more knowledgeable about marine issues than other coastal residents. This suggests that having an economic stake in the marine environment may be a strong motivation to become better educated about the ocean. The fact that all commercial marine users in our study also used the local marine environment on an almost daily basis may also contribute to their greater knowledge. Since the frequencies of both recreational and commercial use 
were significant factors increasing ocean knowledge, creating more opportunities for public engagement in marine activities, and enhancing education and outreach programs with activity-based elements, may not only increase public ocean literacy, but help reduce the knowledge gap between commercial marine users and other coastal residents. Creating more equal knowledge among all groups would enhance engagement by the public in coastal and marine decision-making processes.

High self-assessed and factual knowledge were both associated with use of particular information sources. Both TV and social media seem to have negative effects on ocean knowledge. Fauville et al. (2015) also found that social media, such as Facebook, seem to be of limited value in raising public knowledge about the ocean and offer only limited opportunities for developing ocean knowledge through social participation. Understanding which information sources are associated with higher knowledge will be valuable for increasing the effectiveness of ocean outreach efforts. This might be achieved by improving the content on marine issues in less effective media, by providing more opportunities for interactive discussions and social interactions in social media that might improve the effectiveness of this media, and by increasing information on marine issues in forms found to be effective in increasing public knowledge. Information provided by governmental marine organizations (e.g., MPA management staff), non-governmental organizations, interest groups, and scientific institutions, for example, seem to be effective means for increasing public knowledge. Marine organizations and institutions of higher education thus seem to play an important role in shaping public ocean literacy and increase ocean knowledge among coastal residents living near universities and marine protected areas. Increasing public access to information distributed by these organizations beyond local residents may also foster higher ocean-related knowledge among the public in more distant geographic locations.

\section{Conclusions}

As the general public and other marine stakeholders are becoming more engaged in coastal and marine planning and management processes, fostering a sufficient knowledge base about implications of marine and coastal policies and developments among all groups involved in decision-making processes is critical. This study assessed knowledge about impacts on marine ecosystems due to seawater desalination, an emergent ocean sector. Results demonstrated that both trans-situational and situationspecific variables shape knowledge about marine processes and impacts, and provide insights on factors that shape environmental knowledge of the ocean. Increasing opportunities to engage with the marine 
environment, and targeted outreach and education efforts should increase public knowledge about the ocean irrespective of one's socio-economic status. Such educational efforts should emphasize physical and chemical processes to address specific ocean knowledge gaps, and should target and engage women to address the gender gap in ocean literacy. In addition, expanding accurate ocean-related information in all media venues, particularly those used more frequently by the public, is important. Future studies could also provide more insights on drivers of knowledge among different marine user groups, including commercial fishermen, to determine how different groups learn about the ocean, and then evaluate which groups possess the most relevant knowledge for active engagement in effective coastal and marine decision-making processes.

\section{Acknowledgements}

The study was funded by the National Science Foundation Coastal SEES Program, award $\underline{1325649}$ to A.P., D.P., and B.H. We thank Brolin Mirza and Sarah Faraola for their help in the field.

\section{References}

Beldon, R.S. 1999. Communicating about Oceans: Results of a National Survey. Washington DC.

Capstick, S.B., Pidgeon, N.F., Corner, A.J., Spence, E.M., and Pearson, P.N. 2016. "Public understanding in Great Britain of ocean acidification." Nature Climate Change 6 (8):763.

Cicin-Sain, B., and Knecht, R. 2000. The future of US ocean policy: choices for the new century: Island Press.

Compas, E., Clarke, B., Cutler, C., and Daish, K. 2007. "Murky waters: Media reporting of marine protected areas in South Australia." Marine Policy 31 (6):691-697. doi: http://dx.doi.org/10.1016/j.marpol.2007.03.001.

Einav, R., Harussi, K., and Perry, D. 2003. "The footprint of the desalination processes on the environment." Desalination 152 (1):141-154.

El Wahab, M.A., and Hamoda, A.Z. 2012. "EFFECT OF DESALINATION PLANTS ON THE MARINE ENVIRONMENT ALONG THE RED SEA, EGYPT.(CASE STUDY)." An International Journal of Marine Sciences 28 (2):27-36.

Fauville, G., Dupont, S., von Thun, S., and Lundin, J. 2015. "Can Facebook be used to increase scientific literacy? A case study of the Monterey Bay Aquarium Research Institute Facebook page and 
ocean literacy." Computers \& Education 82:60-73. doi:

http://dx.doi.org/10.1016/j.compedu.2014.11.003.

Fletcher, S., Potts, J.S., Heeps, C., and Pike, K. 2009. "Public awareness of marine environmental issues in the UK." Marine Policy 33 (2):370-375.

Fuentes-Bargues, J.L. 2014. "Analysis of the process of environmental impact assessment for seawater desalination plants in Spain." Desalination 347:166-174. doi: http://dx.doi.org/10.1016/j.desal.2014.05.032.

Fung, A. 2015. "Putting the public back into governance: The challenges of citizen participation and its future." Public Administration Review 75 (4):513-522.

Guest, H., Lotze, H.K., and Wallace, D. 2015. "Youth and the sea: Ocean literacy in Nova Scotia, Canada." Marine Policy 58:98-107.

Guzman, G. 2009. "What is practical knowledge?" Journal of Knowledge Management 13 (4):86-98. doi: doi:10.1108/13673270910971851.

Jefferson, R.L., Bailey, I., Laffoley, D.d.A., Richards, J.P., and Attrill, M.J. 2014. "Public perceptions of the UK marine environment." Marine Policy 43 (0):327-337. doi: http://dx.doi.org/10.1016/j.marpol.2013.07.004.

Jones, N., Panagiotidou, K., Spilanis, I., Evangelinos, K.I., and Dimitrakopoulos, P.G. 2011. "Visitors' perceptions on the management of an important nesting site for loggerhead sea turtle (Caretta caretta L.): The case of Rethymno coastal area in Greece." Ocean \& Coastal Management 54 (8):577-584. doi: http://dx.doi.org/10.1016/j.ocecoaman.2011.05.001.

Latteman, S. 2009. "Protecting the marine environment." In Seawater Desalination - Conventional and Renewable Energy Processes, edited by A Cipollina, G Micale and L Rizzuti. Heidelberg: Springer.

Lattemann, S., and Höpner, T. 2008. "Environmental impact and impact assessment of seawater desalination." Desalination 220 (1-3):1-15. doi: http://dx.doi.org/10.1016/j.desal.2007.03.009.

Levine, M., Serio, N., Radaram, B., Chaudhuri, S., and Talbert, W. 2015. "Addressing the STEM gender gap by designing and implementing an educational outreach chemistry camp for middle school girls." Journal of Chemical Education 92 (10):1639-1644.

Liu, T.-K., Sheu, H.-Y., and Tseng, C.-N. 2013. "Environmental impact assessment of seawater desalination plant under the framework of integrated coastal management." Desalination 326 (0):10-18. doi: http://dx.doi.org/10.1016/j.desal.2013.07.003.

Lovrich, N., and Pierce, J. 1984. "“Knowledge gap" phenomena: Effect of Situation-Specific and Transsituational Factors." Communication Research 11 (3):415-434. doi: $10.1177 / 009365084011003005$. 
Marre, J.-B., Pascoe, S., Thébaud, O., Jennings, S., Boncoeur, J., and Coglan, L. 2016. "Information preferences for the evaluation of coastal development impacts on ecosystem services: A multicriteria assessment in the Australian context." Journal of Environmental Management 173:141150. doi: http://dx.doi.org/10.1016/j.jenvman.2016.01.025.

National Ocean Council. 2013. National Ocean Policy Implementation Plan. Washington, D.C.: National Ocean Council,.

NOAA. 2017. "Monterey Bay National Marine Sanctuary Overview."

NOAA Monterey Bay National Marine Sanctuary, and National Marine Fisheries Service. 2010. "Guidelines for desalination plants in the Monterey Bay National Marine Sanctuary."

O’Bryhim, J.R., and Parsons, E. 2015. "Increased knowledge about sharks increases public concern about their conservation." Marine Policy 56:43-47.

Perry, E.E., Needham, M.D., Cramer, L.A., and Rosenberger, R.S. 2014. "Coastal resident knowledge of new marine reserves in Oregon: The impact of proximity and attachment." Ocean \& Coastal Management 95:107-116. doi: http://dx.doi.org/10.1016/j.ocecoaman.2014.04.011.

Pierce, J.C. 1992. Citizens, political communication, and interest groups: Environmental organizations in Canada and the United States: Praeger Publishers.

Rogers, A.A. 2013. "Public and expert preference divergence: evidence from a choice experiment of marine reserves in Australia." Land Economics 89 (2):346-370.

Steel, B., Lovrich, N.P., Lach, D., and Fomenko, V. 2005a. Correlates and consequences of public knowledge concerning ocean fisheries management. In Coastal Management.

Steel, B., Smith, C., Opsommer, L., Curiel, S., and Warner-Steel, R. 2005b. "Public ocean literacy in the United States." Ocean \& Coastal Management 48 (2):97-114. doi: http://dx.doi.org/10.1016/j.ocecoaman.2005.01.002.

Steel, B.S., Soden, D.L., and Warner, R.L. 1990. "The impact of knowledge and values on perceptions of environmental risk to the Great Lakes." Society \& Natural Resources 3 (4):331-348.

Vanclay, F. 2012. "The potential application of social impact assessment in integrated coastal zone management." Ocean \& Coastal Management 68:149-156. doi: http://dx.doi.org/10.1016/j.ocecoaman.2012.05.016.

Wiener, C.S., Manset, G., and Lemus, J.D. 2016. "Ocean use in Hawaii as a predictor of marine conservation interests, beliefs, and willingness to participate: an exploratory study." Journal of Environmental Studies and Sciences 6 (4):712-723.

Xu, J., Chen, L., Lu, Y., and Fu, B. 2006. "Local people's perceptions as decision support for protected area management in Wolong Biosphere Reserve, China." Journal of Environmental Management 78 (4):362-372. doi: http://dx.doi.org/10.1016/j.jenvman.2005.05.003. 
